\title{
Correction of "A Recruitment Forecasting Model for the Pacific Stock of the Japanese Sardine (Sardinops melanostictus) That Does Not Assume Density-Dependent Effects"
}

\author{
Kazumi Sakuramoto \\ Department of Ocean Science and Technology, Tokyo University of Marine Science and Technology, Tokyo, Japan \\ Email: sakurak@kaiyodai.ac.jp
}

How to cite this paper: Sakuramoto, K. (2017) Correction of "A Recruitment Forecasting Model for the Pacific Stock of the Japanese Sardine (Sardinops melanostictus) That Does Not Assume Density-Dependent Effects". Open Access Library Journal, 4: e3620.

https://doi.org/10.4236/oalib.1103620

Received: April 19, 2017

Accepted: May 20, 2017

Published: May 23, 2017

Copyright (๑) 2017 by author and Open Access Library Inc.

This work is licensed under the Creative Commons Attribution International License (CC BY 4.0).

http://creativecommons.org/licenses/by/4.0/

\section{c) (†) Open Access}

\begin{abstract}
One error was found in the coding of the simulation program for reproducing the recruitment (R) and spawning stock biomass (SSB) of the Pacific stock of the Japanese sardine. As a result of this error, the maturity rate for age 1 in the simulation was found to be half of the value cited from the literature. The aim of this paper is to show the results when the error is corrected. When the error was corrected, the reproduced R and SSB were slightly higher than the values shown in the previous paper. When the fishing mortality coeffcients (F) before 2003 and after 2004 were assumed to be 10\% higher and 50\% lower than the values cited, respectively, the results coincided better with R and SSB cited. The only difference between the simulation conducted in this paper and that conducted in the previous paper is the assumption that the value of $\mathrm{F}$ before 2003 was $10 \%$ higher than the values cited. Therefore, the effect of the error was not serious, and the essential conclusions noted in the previous paper did not change.
\end{abstract}

\section{Subject Areas}

Marine Biology

\section{Keywords}

Pacific Stock of Japanese Sardine, Stock-Recruitment Relationship, Environmental Factors, Arctic Oscillation

\section{Introduction}

Among Japanese fisheries, the Japanese sardine (Sardinops melanostictus) is one of the most important species in the northwestern Pacific. In 1997, the Japanese 
Government introduced a total allowable catch (TAC) system for seven species including sardine. Sardine numbers began to increase during the 1960s and were very high in the 1980s, but decreased markedly in the early 1990s and have remained low. Since the TAC system was introduced, many fishermen who harvest sardine have opposed the schemes for management of the depleted populations. The government of Japan insists that a reduction in the TAC is necessary to rehabilitate the sardine population, but the fishermen insist that a reduction is not appropriate because the fluctuations in sardine population abundance are mainly caused by environmental factors. To establish management schemes that are acceptable to fishermen but meet government management objectives, fisheries scientists need new models of sardine population abundance that can explain the extremely large fluctuations in recruitment and the spawning stock biomass.

Sakuramoto proposed a new stock-recruitment relationship for the Pacific stock of the Japanese sardine [1] that incorporates environmental factors instead of assuming a density-dependent effect. The estimated model shown in the previous paper was expressed as follows [1]:

$$
\begin{aligned}
\ln \left(R P S_{t}\right)= & 15.713-0.108 A O_{t}^{2}-0.0745 A O_{t}^{3}-0.0011 K E S T_{t}^{3} \\
& +0.0187 A O_{t} \times K E S T_{t}
\end{aligned}
$$

where $A O_{t}$ and $K E S T_{t}$ respectively denote the Arctic oscillation (AO) in February of year $t$ and the sea surface temperature over the southern area of the Kuroshio Extension from $30^{\circ} \mathrm{N}$ to $35^{\circ} \mathrm{N}$ and $145^{\circ} \mathrm{E}$ to $180^{\circ} \mathrm{E}$ (KEST) in February. The natural logarithm of the recruitment per spawning stock biomass (RPS) is denoted by $\ln (\mathrm{RPS})$. Using Equation (1), R and SSB were reproduced provided that the numbers of fish by age in 1976 were given as the initial values and that environmental factors such as AO and KEST were known. The procedure by which $\mathrm{R}$ and SSB were reproduced was explained in detail in the previous paper [1]. However, it was recently found that one line in the program that calculates the matured stock was miscoded. The aim of this paper is to show the results when the error is corrected.

\section{Methods}

\subsection{Data}

In this study, I used values for the catch, average weight, maturity rate, and natural mortality coefficient, all of which are recorded by age and year, for the northwestern Pacific stock from 1976 to 2012 [2]. The number of fish and the fishing mortality coefficients by age in each year estimated by the tuning virtual population analysis (tuning VPA) [2]. AO in February was obtained from the

NOAA Climate Prediction Center [3]. The sea surface temperature over the southern area of the Kuroshio Extension from $30^{\circ} \mathrm{N}$ to $35^{\circ} \mathrm{N}$ and $145^{\circ} \mathrm{E}$ to $180^{\circ} \mathrm{E}$ (KEST) in February was furnished by the Japan Meteorological Agency [4].

\subsection{Simulation Program Coded with MATLAB Software}

The simulation program was coded with MATLAB software Version R2013b. 
The incorrect sentence in the program is as follows:

$$
\operatorname{Stcal}(t+1)=\operatorname{Stcal}(t+1)+\operatorname{mature}(t+1, a) * \operatorname{SSBcal}(t+1, a),
$$

where Stcal $(t+1)$, mature $(t+1, a)$, and SSBcal $(t+1, a)$ denote the reproduced values of SSB in year $t+1$, the maturity rate at age $a$ in year $t+1$, and the reproduced values of SSB at age $a$ in year $t+1(a=0,1, \cdots, 5+)$, respectively. The line should be replaced by the following:

$$
\operatorname{Stcal}(t+1)=\operatorname{Stcal}(t+1)+\operatorname{SSBcal}(t+1, a) .
$$

That is, the maturity rate, mature $(t+1, a)$, in Equation (2) should be removed. As a result of this error, the maturity rate for age 1 was doubly multiplied. The maturity rate for age 0 is zero, and those for ages 2 and older are unity; therefore, the values calculated with Equations (2) and (3) are not different for ages 0 and for ages 2 and older. However, the maturity rate for age 1 cited is 0.5 . When Equation (2) is used, the rate of matured fish at age 1 is wrongly calculated by multiplying $0.5 * 0.5=0.25$ by the number of fish at the age of 1 . That is, the calculated number of matured fish at age 1 was half of the true value. This caused the underestimation of $\mathrm{R}$ and SSB.

\subsection{When Corrected Program Was Used}

In the previous paper, the fishing mortality coefficients after 2004 were halved so as to minimize the differences between the values cited and reproduced of $R$ and SSB after 2004, because the reproduced R and SSB were much smaller than those cited from the literature [2]. This additional modification of $\mathrm{F}$ might be necessary in response to the error. The first examination shows the results when the program is corrected and $\mathrm{F}$ is not changed after 2004 and the value of F cited is used. The second examination shows the results when the corrected program and half the value of $\mathrm{F}$ after 2004 are used. The third examination shows the results when the corrected program, a $10 \%$ lower F value before 2003 , and half the value of $\mathrm{F}$ after 2004 are used. The fourth examination shows the results when the corrected program with $\mathrm{F}$ value cited, a 5\% larger $\mathrm{M}$ value before 2003, and a $90 \%$ lower M value after 2004 are used. The scenarios are summarized in Table 1.

\section{Results}

\section{Reproductions of R and SSB When the Error Is Corrected}

Figure 1 shows the reproduced R and SSB under scenario 1, which are shown in red lines. That is, Equation (3) was used and the values of $\mathrm{F}$ and $\mathrm{M}$ cited from the literature [2] were used. The results showed that R and SSB were slightly larger than the values cited, and those shown in the previous paper. However, the reproduced R after 2005 and SSB after 2006 were much smaller, and were the same as those shown in the previous paper.

Figure 2 shows the reproduced R and SSB values under scenario 2. That is, Equation (3) was used and the value of F cited after 2004 was replaced with 50\% 


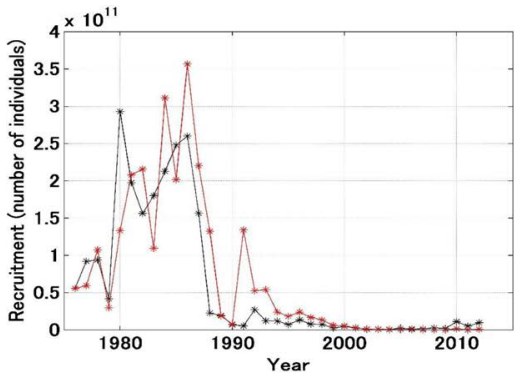

(a)

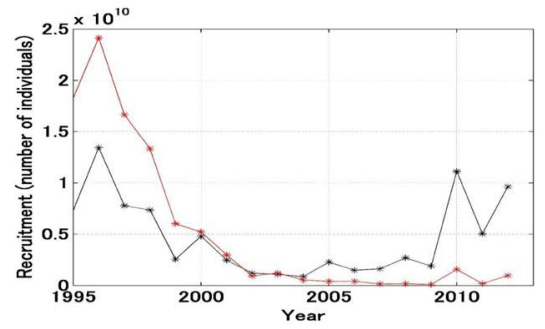

(b)

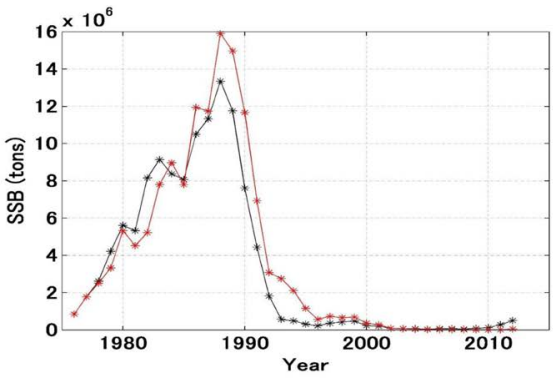

(b)

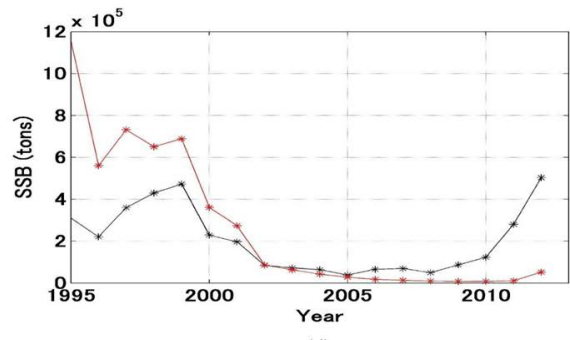

(d)

Figure 1. R and SSB cited (black) and reproduced (red) under scenario 1. (a) Recruitment; (b) Recruitment (enlarged scale); (c) SSB; (d) SSB (enlarged scale).

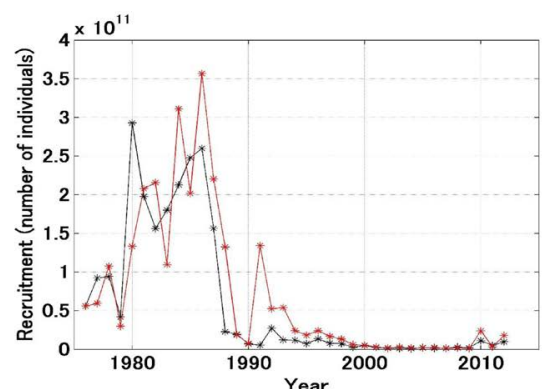

(a)

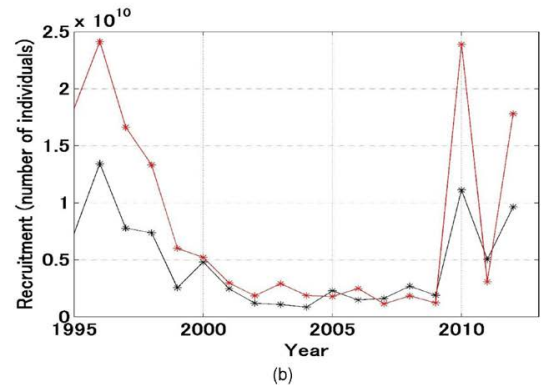

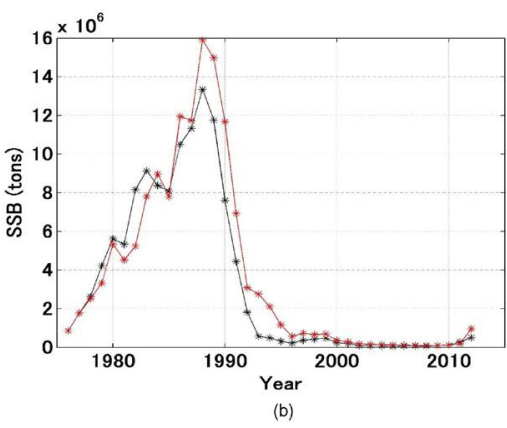

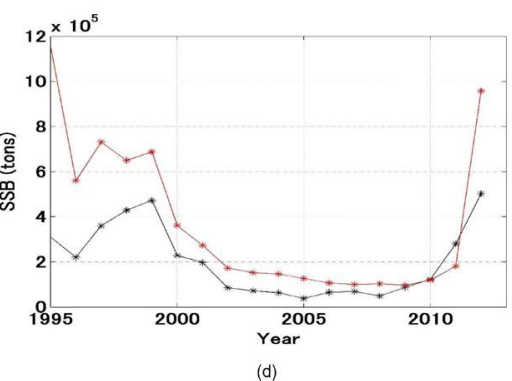

Figure 2. R and SSB cited (black) and reproduced (red) under scenario 2. (a) Recruitment; (b) Recruitment (enlarged scale); (c) SSB; (d) SSB (enlarged scale).

Table 1. Scenarios examined in the simulations. $\mathrm{F}$ and $\mathrm{M}$ denote the values cited from the literature [2].

\begin{tabular}{cccccc}
\hline Scenario & $\mathrm{F}(1976-2003)$ & $\mathrm{F}(2004-2012)$ & $\mathrm{M}(1976-2003)$ & $\mathrm{M}(2004-2012)$ & Figure \\
\hline 1 & $\mathrm{~F}$ & $\mathrm{~F}$ & $\mathrm{M}$ & $\mathrm{M}$ & Figure 1 \\
2 & $\mathrm{~F}$ & $0.50 \mathrm{~F}$ & $\mathrm{M}$ & $\mathrm{M}$ & Figure 2 \\
3 & $1.10 \mathrm{~F}$ & $0.50 \mathrm{~F}$ & $\mathrm{M}$ & $\mathrm{M}$ & Figure 3 \\
4 & $\mathrm{~F}$ & $\mathrm{~F}$ & $1.05 \mathrm{M}$ & $0.10 \mathrm{M}$ & Figure 4
\end{tabular}


of the value. In this case, the reproduced R after 2005 and SSB values after 2006 were larger than those in Figure 1. In scenario 2, the reproduced $\mathrm{R}$ values in 2010 and 2012 and the SSB value in 2012 were very high.

Figure 3 shows the reproduced $\mathrm{R}$ and SSB values under scenario 3 . That is, Equation (3) was used and not only was the value of $\mathrm{F}$ after 2004 replaced with $50 \%$ of the value cited, but the value of $\mathrm{F}$ before 2003 was also replaced by a value $10 \%$ higher. That is, $\mathrm{F}$ times 1.1 was used as the fishing mortality coefficient before 2003. In this case, the reproduced R and SSB values before 2003 coincided better with those cited, and the reproduced R and SSB values after 2004 also coincided well with those cited.

Figure 4 shows the reproduced $\mathrm{R}$ and SSB values under scenario 4 . That is, Equation (3) was used and the value of F cited was used for all years. However, the value of $\mathrm{M}$ before 2003 was replaced by a value $5 \%$ higher than the value cited, and the value of $\mathrm{M}$ after 2004 was replaced by only $10 \%$ of the value cited. That is, $\mathrm{M}$ times 1.05 was used before 2003 and 0.04 (0.4 times 0.1 ) was used as the natural mortality coefficient after 2004. In this case, the reproduced $\mathrm{R}$ and SSB values before 2003 coincided well with those cited, and the fitting of the reproduced R and SSB values after 2004 was also improved, although the latter assumption seems to be unrealistic.

\section{Discussion}

This paper showed the results when the error in the program was corrected. There was a tendency for the reproduced R and SSB values before 2003 to be slightly large, and for those after 2005 to be much lower than the values cited. Three possibilities were considered as interpretations of this phenomenon. One is that actual $\mathrm{F}$ before 2003 was higher than the values cited and actual $\mathrm{F}$ after
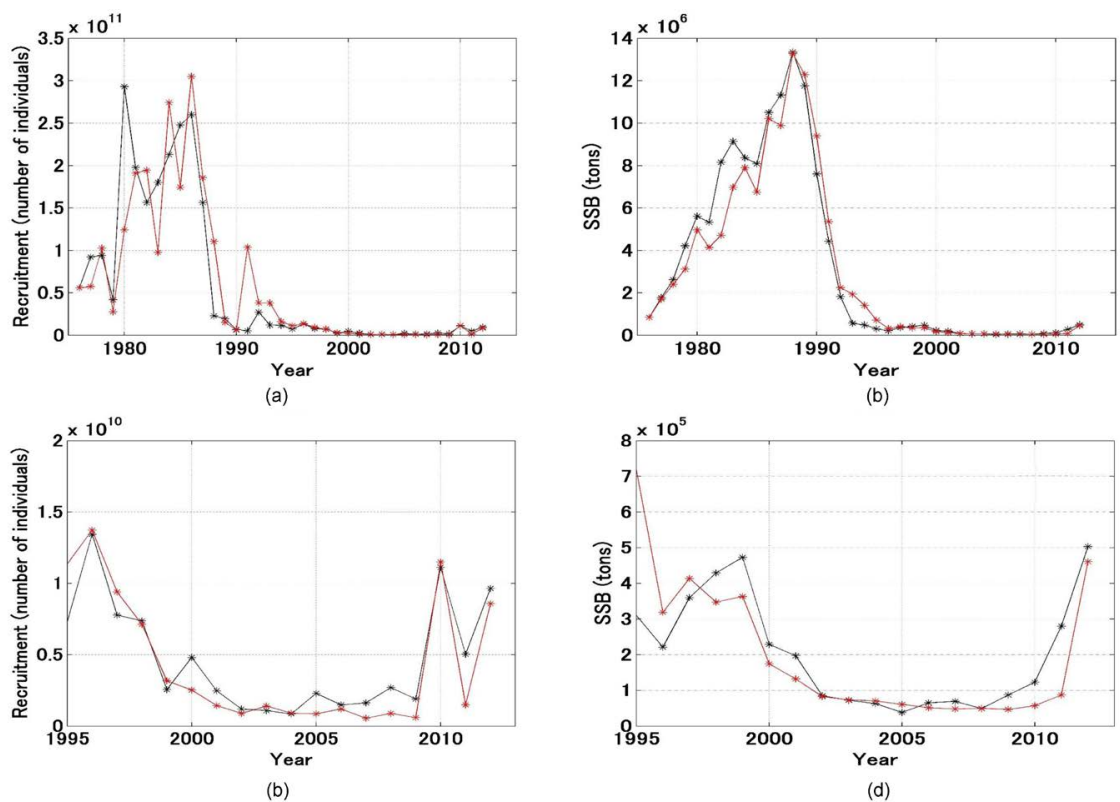

Figure 3. R and SSB cited (black) and reproduced (red) under scenario 3. (a) Recruitment; (b) Recruitment (enlarged scale); (c) SSB; (d) SSB (enlarged scale). 

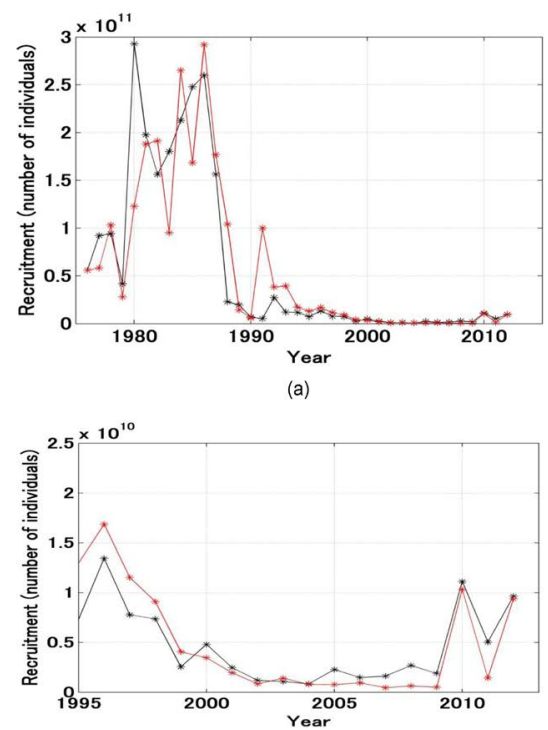

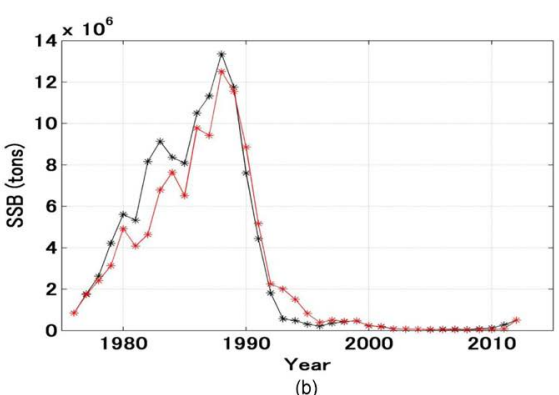

(b)

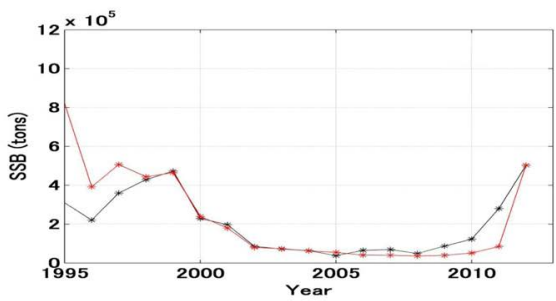

(d)

Figure 4. R and SSB cited (black) and reproduced (red) under scenario 4. (a) Recruitment; (b) Recruitment (enlarged scale); (c) SSB; (d) SSB (enlarged scale).

2004 was lower than the values to be referred. When we assumed that $\mathrm{F}$ before 2003 was $10 \%$ higher than the values cited and F after 2004 was $50 \%$ lower than the values cited, the reproduced $\mathrm{R}$ and SSB values coincided well with those cited. The second possibility is that true $\mathrm{M}$ before 2003 was higher than the value cited and true $\mathrm{M}$ after 2004 was lower than the value cited. When we assumed that true $\mathrm{M}$ before 2003 was $5 \%$ higher than the value cited and true $\mathrm{M}$ after 2004 was $90 \%$ lower than the value cited, the reproduced R and SSB values coincided well with those cited. However, the latter assumption, in which $\mathrm{M}$ after 2004 was $10 \%$ of the value cited, was extremely low and was considered to be unrealistic. The third possibility is that the above two scenarios were combined. Although using an M value after 2004 that was $10 \%$ of the value cited was unrealistic, for the other scenarios we cannot determine which value was more realistic at this stage.

Although the aim of this study is not to find the best parameters that give the best fit to $\mathrm{R}$ and SSB cited, we could determine the best combination of $\mathrm{F}$ and $\mathrm{M}$ that minimize the differences between the values reproduced and cited of $\mathrm{R}$ and SSB. Other parameters, such as the mean weight of fish by age and the maturity rate by age, are also important. All of those parameters fluctuate year by year; therefore, if we can use the accurate values of $\mathrm{F}, \mathrm{M}$, the maturity rate by age, and the mean weight by age for each year, the fitting of the reproduced values to those cited would be much batter.

The same correction was conducted for the paper on Pacific bluefin tuna that was analyzed by Sakuramoto [5] [6]. In the case of Pacific bluefin tuna, the effect of the error was more serious than in this case, because the error influenced the maturity rates for ages 3 and 4 . That is, the maturity rate for age 3 cited was 0.2 , and the uncorrected maturity rate for age 3 was then extremely low (0.04). The 
maturity rate for age 4 cited was 0.5 , and the uncorrected maturity rate for age 4 was half of the value (0.25), which corresponded to the case of the Pacific stock of the Japanese sardine. Therefore, when the error was corrected, the reproduced $\mathrm{R}$ and SSB values for Pacific bluefin tuna became higher than those for the Pacific stock of the Japanese sardine.

\section{Conclusion}

When the error in the program was corrected, the results did not change greatly from those obtained when the wrong program was used. When the value of $\mathrm{F}$ to be referred before 2003 was replaced by a value $10 \%$ higher than the value cited and the value of $\mathrm{F}$ after 2004 was replaced with $50 \%$ of the value cited, the reproduced $\mathrm{R}$ and SSB values coincided well with those cited. Therefore, the effect of the error was not serious, and the essential conclusions noted in the previous paper did not change.

\section{Acknowledgements}

I would like to thank KN International for improving the manuscript.

\section{References}

[1] Sakuramoto, K. (2013) A Recruitment Forecasting Model for the Pacific Stock of the Japanese Sardine (Sardinops melanostictus) That Does Not Assume Density-Dependent Effects. Agricultural Science, 4, 1-8. https://doi.org/10.4236/as.2013.46a001

[2] Kawabata, J., Honda, S., Watanabe, C., Okamura, H. and Ichinokawa, M. (2014) Stock Assessment and Evaluation for the Pacific Stock of Japanese Sardine (Fiscal Year 2013). In Marine Stock Fisheries Stock Assessment and Evaluation for Japanese Waters (Fiscal Year 2013/2014), Japan Fisheries Research and Education Agency, 15-46.

[3] AO (Arctic Oscillation), NOAA Climate Prediction Center. (2015) Web: http://www.cpc.ncep.noaa.gov/products/precip/CWlink/daily_ao_index/monthly.a o.index.b50.current.ascii

[4] COBE-SST. http://ds.data.jma.go.jp/tcc/tcc/products/elnino/cobesst/cobe-sst.html

[5] Sakuramoto, K. (2016) Case Study: A Simulation Model of the Spawning Stock Biomass of Pacific Bluefin Tuna and Evaluation of Fisheries Regulations. American Journal of Climate Change, 5, 245-260. https://doi.org/10.4236/ajcc.2016.52021

[6] Sakuramoto, K. (2017) Correction of "A Case Study: A Simulation Model of the Spawning Stock Biomass of Pacific Bluefin Tuna and Evaluation of Fisheries Regulations". Open Access Library Journal, 4: e3575.

https://doi.org/10.4236/oalib.1103575 
Submit or recommend next manuscript to OALib Journal and we will provide best service for you:

- Publication frequency: Monthly

- 9 subject areas of science, technology and medicine

- Fair and rigorous peer-review system

- Fast publication process

- Article promotion in various social networking sites (LinkedIn, Facebook, Twitter, etc.)

- Maximum dissemination of your research work

Submit Your Paper Online: Click Here to Submit

Or Contact service@oalib.com 